\title{
Prevalence of gastrointestinal bleeding and frequency of selected predictors of mortality on the Medical Emergency Ward at Mulago Hospital
}

IVAN KISUULE ( $\boldsymbol{D}$ ivankisuule@yahoo.com )

Mulago hospital

Emmanuel Seremba

Mulago National Referral Hospital

Magid Kagimu

Makerere University College of Health Sciences

Research article

Keywords: Gastrointestinal bleeding, Casualty assessment form, Emergency ward

Posted Date: January 20th, 2020

DOI: https://doi.org/10.21203/rs.2.21310/v1

License: (c) (i) This work is licensed under a Creative Commons Attribution 4.0 International License.

Read Full License 


\section{Abstract}

\section{Background}

Gastroenterologists of Mulago hospital noted that many patients with gastrointestinal bleeding are transferred to their ward from the emergency ward without adequate resuscitation. They recommended that blood should be ring fenced for patients with gastrointestinal bleeding (GI) on the emergency ward so that urgent resuscitation can be done. There was however no current data on the prevalence of GI bleeding in the emergency ward to provide a guide of how much blood should be ring fenced. This was partly because the medical records are not adequately completed as designed. We thus undertook a study to estimate the prevalence of GI bleeding on the emergency ward by incorporating quality improvement methods in the process of data collection to improve the documentation practice on the Casualty assessment form (CAF).

Methods

This was a cross sectional study incorporating quality improvement methods in the process of data collection from the CAF for patients attending the emergency ward. Focus group discussions and key informant interviews were conducted to ascertain the root causes of inadequate completion of this form. The health care team was educated on documentation of GI bleeding while being assessed weekly for knowledge and practice of completion of the CAF. The filled CAF were assessed for adequate completion while looking out for a documented diagnosis of GI bleeding and selected predictors of mortality.

Results

Of the $1881 \mathrm{CAF}$ assessed, $278 \mathrm{had}$ a documented diagnosis of $\mathrm{GI}$ bleeding, resulting in a prevalence of $6.8 \%$. Of the patients with GI bleeding, $14.1 \%$ of them had age greater than 60 years old, $24.0 \%$ had a systolic blood pressure less than $100 \mathrm{mmHg}$ and $44.5 \%$ had a heart rate greater than 100 beats per minute.

\section{Conclusion}

The prevalence of GI bleeding on the medical emergency ward of Mulago hospital is high, with 1 in every 15 patients having this condition. This calls for strategies for resuscitative management of this potentially life threatening condition. Among the selected predictors of mortality, tachycardia was most frequent followed by hypotension. These should always be assessed in a patient with GI bleeding and resuscitative measures with blood transfusion and intravenous fluids undertaken to correct them.

\section{Background}

Gastrointestinal bleeding is classified as upper or lower gastrointestinal bleeding, separated anatomically by the ligament of Treitz. Acute upper gastrointestinal bleeding should be suspected in patients with haematemesis, coffee-ground vomiting, melaena or unexplained fall in haemoglobin. In up to $20 \%$ of 
cases, acute upper gastrointestinal bleeding (AUGIB) may mimic lower gastrointestinal bleeding. Features that predict AUGIB in cases of haematochezia include haemodynamic instability, increased serum urea: creatinine ratio, and reduced haematocrit. The diagnosis is confirmed with endoscopy, which may also serve to provide therapeutic interventions (K. Siau et al., 2017)

Acute lower gastrointestinal bleeding manifests as hematochezia (maroon or red blood passed through the rectum). Uncommonly, lower gastrointestinal bleeding can manifest as melena (black, tarry stools), or, conversely, brisk (rapid) upper gastrointestinal bleeding can manifest as hematochezia (Gralnek, Neeman, \& Strate, 2017).

At the initial encounter with a patient with gastrointestinal bleeding, risk assessment is performed to determine the severity of upper gastrointestinal bleeding according to vital signs and patient factors. Tachycardia (heart rate $\geq 100$ beats per minute), hypotension (systolic blood pressure $\leq 100 \mathrm{~mm} \mathrm{Hg}$ ), age older than 60 years, and major coexisting conditions are associated with an increased risk of further bleeding and death (Rockall, Logan, Devlin, \& Northfield, 1996).

Risk-assessment tools are available and are useful in identifying patients at risk of mortality. For example, discharge from the emergency department followed by outpatient care has been suggested for patients with a Glasgow-Blatchford score of 0,0 to 1, or, in patients who are less than 70 years of age, 0 to 2 (on a scale of 0 to 23, with higher scores indicating higher risk). A prospective study showed that when hospitalized; less than $1 \%$ of such patients require intervention and less than $0.5 \%$ die (Laursen et al., 2015).

There are no current data on the prevalence of GI bleeding and selected predictors of mortality on the medical emergency ward. This is partly because the medical records are not adequately completed as designed. For example, the casualty assessment form was designed to be completed by the health care team and left in the emergency ward after the patient is either discharged or transferred to another ward. Reviewing data from this form if it is adequately completed and left on the emergency ward would provide data that can be used to estimate the prevalence of various conditions. Unfortunately this form is neither regularly adequately completed, nor is it left on the emergency ward in many instances when the patient is being transferred for specialized care. This poor clinical documentation practice in our setting had also been recognized among other challenges that affect optimal care of severely ill patients in resource limited settings(Cummings et al., 2017). In order to obtain a more accurate estimate of the prevalence of $\mathrm{Gl}$ bleeding on the emergency ward it was essential to improve the process of documentation and storage of the data on the casualty assessment form by using quality improvement methods.

A more accurate estimation of the prevalence of gastrointestinal bleeding on the emergency ward of Mulago hospital would inform policy on the burden of this condition and lead to better planning for strategies and resources required to care for these patients such as blood for blood transfusion, drugs like terlipressin and space for resuscitation of these patients. Since the current prevalence of GI bleeding on the emergency ward was not known, proper planning for improving the care of these patients was 
unlikely to be done and some of these patients whose lives could have been saved with adequate resuscitation, might die.

The general objective was to determine the prevalence of $\mathrm{Gl}$ bleeding and selected predictors of mortality among patients admitted on the medical emergency ward of Mulago hospital, so as to generate more accurate information to contribute to improving patient care by using it in planning strategies for adequate resuscitation of these patients.

\section{Methods}

This was a cross-sectional study incorporating quality improvement methods in the process of data collection. The study was conducted on the medical emergency ward of the Directorate of Medicine, Mulago hospital, currently operating in Kiruddu, Kampala, Uganda. This emergency ward has a bed capacity of 25 beds and receives an average of 30 patients in a 24-hour period and 900 patients over a month period. The patients stay in the emergency ward for a short period after which they are either admitted to the specialized ward with respect to their disease or are discharged home if they don't need to be admitted. The emergency healthcare team is composed of eight medical officers, fifteen nurses, four intern doctors and one physician. These were the members of the health team we primarily targeted to get involved in the study.

Casualty assessment forms of all patients attending the medical emergency ward of Mulago national referral hospital during the study period were assessed for adequate completion while looking out for a documented diagnosis of GI bleeding and selected predictors of mortality. Consecutive sampling of the casualty assessment forms which were filled by the quality improvement team during the study period of 13 weeks was done.

The data were collected using a data collection tool by the principal investigator and research assistants who first conducted the focus group discussions and key informant interviews to find out the root causes of inadequate completion of the CAF and then did education sessions with ongoing knowledge and CAF completion assessment.

Data analysis and management

Data collected were entered into the computer using EPI-DATA (version 3.1) software to minimize data entry errors and exported to STATA/IC 11.0 for analysis. Data were then backed up and archived in both soft and hard copies to avoid loss. Confidentiality was ensured by de-identification using numbers instead of patients' names. Qualitative data were recorded by the notes taker and then transcribed into themes to aid in data analysis.

\section{Results}


The study was conducted between July and October 2018. We used quality improvement methods in the process of data collection so that we could estimate the prevalence of Gl bleeding on the emergency ward of Mulago hospital with more accuracy. The QI methods included mapping of the documentation process, identifying the root causes of inadequate documentation through focus group discussions and key informant interviews, intervening by educating health workers on the emergency ward regarding documentation on the CAF and then assessed the trend of completion of the form while looking out for the documented diagnosis of GI bleeding and the selected predictors of mortality namely age, systolic blood pressure and pulse rate. The following were the results of these assessments.

Social-demographic characteristics of the study participants

The social-demographic characteristics of the study participants have been categorized between two groups; those of the entire study participants and those who had a documented diagnosis of GI bleeding. The characteristics of the former group are summarized in Table 1 below while for the latter group in Table 2. Among those with a diagnosis of GI bleeding, majority were male $77(60.2 \%)$, of Catholic faith 44 (34.4\%) and from central Uganda 60 (46.9\%). 
Table 1

Demographic characteristics of all the study participants

\begin{tabular}{|lll|}
\hline Characteristic & Frequency $(\mathbf{N}=1881)$ & Percentage \\
\hline Age (mean, SD) & $43.9,( \pm 19.6)$ & \\
\hline Sex & & 50.0 \\
\hline Male & 941 & 48.8 \\
\hline Female & 917 & 1.2 \\
\hline Not recorded & 23 & \\
\hline Religion & & 17.0 \\
\hline Muslim & 319 & 32.2 \\
\hline Catholic & 605 & 1.3 \\
\hline Anglican & 24 & 28.0 \\
\hline Pentecostal & 527 & 10.9 \\
\hline Others & 205 & 10.6 \\
\hline Not recorded & 200 & \\
\hline Occupation & & 33.7 \\
\hline Employed & 634 & 30.7 \\
\hline Not employed & 578 & 8.9 \\
\hline Others & 168 & 26.6 \\
\hline Not recorded & 500 & \\
\hline Region of origin & & 5.9 \\
\hline Central & 996 & \\
\hline West & 383 & \\
\hline East & 230 & \\
\hline North & 85 & \\
\hline Not recorded & 187 & \\
\hline
\end{tabular}


Table 2

Demographic Characteristics of patients with GI bleeding

\begin{tabular}{|c|c|c|}
\hline Characteristic & Frequency $(\mathrm{N}=128)$ & Percentage \\
\hline Age (mean, SD) & $41.3,17.2$ & \\
\hline \multicolumn{3}{|l|}{ Sex } \\
\hline Male & 77 & 60.2 \\
\hline Female & 51 & 39.8 \\
\hline \multicolumn{3}{|l|}{ Religion } \\
\hline Muslim & 18 & 14.1 \\
\hline Catholic & 44 & 34.4 \\
\hline Anglican & 3 & 2.3 \\
\hline Pentecostal & 35 & 27.3 \\
\hline Others & 19 & 14.8 \\
\hline Not recorded & 9 & 7.0 \\
\hline \multicolumn{3}{|l|}{ Occupation } \\
\hline Employed & 49 & 38.3 \\
\hline Not employed & 43 & 33.6 \\
\hline Others & 8 & 6.3 \\
\hline Not recorded & 28 & 21.9 \\
\hline \multicolumn{3}{|l|}{ Region of origin } \\
\hline Central & 60 & 46.9 \\
\hline West & 31 & 24.2 \\
\hline East & 16 & 12.5 \\
\hline North & 9 & 7.0 \\
\hline Not recorded & 12 & 9.4 \\
\hline
\end{tabular}

Prevalence of gastrointestinal bleeding

Out of the 1881 CAFs assessed during the study period, 128 of these forms had a documented diagnosis of gastrointestinal bleeding, giving an overall prevalence of $6.8 \%$. The weekly prevalence ranged between $3.2 \%$ and $9.8 \%$. These findings are presented on the run chart in Fig. 1 below. 


\begin{tabular}{|lll|}
\hline Characteristic & Frequency $(\mathbf{N}=128)$ & Percentage \\
\hline Improved & 5 & 3.9 \\
\hline Unimproved & 121 & 94.5 \\
\hline Died & 2 & 1.6 \\
\hline Prevalence of gastrointestinal bleeding & & \\
\hline $\begin{array}{l}\text { Out of the 1881 CAFs assessed during the study period, } 128 \text { of these forms had a documented } \\
\text { diagnosis of gastrointestinal bleeding, giving an overall prevalence of 6.8\%. The weekly prevalence } \\
\text { ranged between 3.2\% and 9.8\%. These findings are presented on the run chart in Fig. 1 below. }\end{array}$ \\
\hline
\end{tabular}

Predictors of mortality among patients with gastrointestinal bleeding

The selected clinical characteristics which predict a high risk of mortality among patients with GI bleeding were age, systolic blood pressure and pulse rate. The median age of patients with GI bleeding was 39 years with interquartile range of 13 to 80 years. Only $18(14.1 \%)$ patients were greater than 60 years of age. Hypotension (systolic blood pressure less than $100 \mathrm{mmHg}$ ) was observed in $30(24.0 \%)$ patients while tachycardia (pulse rate greater than 100 beats per minute) was recorded for $57(44.5 \%)$ of the patients. Further, $15(11.7 \%)$ of the patients had both hypotension and tachycardia. Only one patient had age greater than 60 years, hypotension and tachycardia. Two patients died on the emergency ward and both had hypotension but were less than 60 years and had no tachycardia. The Table 3 below summarizes these findings.

Table 3

Proportion of GI bleeding patients with selected predictors of mortality

\begin{tabular}{|lll|}
\hline Clinical Parameter & Number of GI Bleeding patients $(\mathbf{N}=128)$ & Proportion \\
\hline Age $>60 \mathrm{yrs}$ & 18 & $14.1 \%$ \\
\hline $\mathrm{SBP}<100 \mathrm{mmHg}$ & 30 & $24.0 \%$ \\
\hline HR $>100 \mathrm{bpm}$ & 57 & $44.5 \%$ \\
\hline NB: Percentages not mutually exclusive. \\
\hline
\end{tabular}

\section{Discussion}

This study aimed to determine the prevalence of gastrointestinal bleeding and the frequency of selected predictors of mortality on the medical emergency ward of Mulago hospital with quality improvement methods incorporated in the process of data collection from the casualty assessment forms (CAF). Before the study was done, the CAF were not being filled adequately and were not being kept on the emergency ward and therefore would not be used to give us an estimate of the prevalence of GI bleeding. We therefore used quality improvement methods to improve the process of documentation on the CAF so 
that we estimate the prevalence of GI bleeding with more accuracy. The results and discussion of the quality improvement methods have been written and submitted for publication separately. The prevalence of GI bleeding obtained after improving the documentation process is more accurate and reflects the burden of this life threatening medical emergency.

We found a prevalence of gastrointestinal bleeding of $6.8 \%$. This is higher than the prevalence of $2.0 \%$ that was found in a Nigerian study (Rukewe, Otegbayo, \& Fatiregun, 2015). However, this study only looked at upper gastrointestinal bleeding at the emergency department of a tertiary hospital in Nigeria and much as it was a retrospective study based on review of medical records, they did not incorporate quality improvement methods in the process of data collection. Indeed, they stated missing data as a major limitation in their study. Other studies in similar resource setting have evaluated causes of GI bleeding (Alema, Martin, \& Okello, 2012), (Alatise et al., 2014), (Harries \& Wirima, 1989) and as such, it is not possible to compare our findings with theirs since we did not study etiology of the Gl bleeding in our study. GI bleeding has been characterized better in high resource settings with incidence rates of 134 per 100,000 in the UK (K Siau et al., 2017) and being the most common cause of hospitalization due to gastrointestinal disease in the United States, accounts for more than 507,000 hospitalizations annually in the US (Peery et al., 2015).

Basing on the Rockall criteria (Rockall et al., 1996) our patients were at a low risk of mortality. This is attributed to the fact that only $14.1 \%$ were above the age of 60 years; hypotension was prevalent in only $24 \%$ and tachycardia in $44.5 \%$. These findings add support to earlier findings that mortality from GI bleeding is largely the result of complications associated with other illnesses(Marmo R, 2008) rather than bleeding to death.

\section{Limitations of the study}

We abstracted the diagnosis of GI bleeding as recorded on the CAF. These were not confirmed by endoscopy. Even with quality improvement measures, the CAF were not completed adequately. However, the estimate of the prevalence may not be far from the true prevalence since the diagnosis field was well completed during the study period.

\section{Conclusions}

The prevalence of GI bleeding on the medical emergency ward of Mulago hospital appeared higher than other resource limited settings with 1 in every 15 patients having this condition. This calls for laying of strategies for resuscitative management of this potentially life threatening medical emergency. Among the selected predictors of mortality, tachycardia was most frequent followed by hypotension. These should always be assessed in a patient with GI bleeding and resuscitative measures with blood transfusion and intravenous fluids undertaken to correct them.

Recommendations 
Basing on the prevalence of GI bleeding on the emergency ward, there is need for creation of triage and resuscitation areas to allow for quick identification and effective emergency care of these patients. In addition, blood and potentially lifesaving medications such as terlipressin and proton pump inhibitors should be ring-fenced and availed for this medical emergency. With 1 in every 15 patients presenting with Gl bleeding in the emergency ward which has an average of 30 patients being admitted in 24 hours, it implies that at least 4 units of blood should always be preserved for transfusion of these patients on a daily basis, assuming each patient needs at least 2 units of blood.

\section{Abbreviations}

CAF: Casualty assessment form, Gl: Gastrointestinal, HR: Heart rate, QI: Quality improvement, SBP: Systolic blood pressure.

\section{Declarations}

\section{Ethical approval and consent to participate}

Approval to conduct the study was sought from the Department of Medicine, Makerere University College of Health Sciences and from the School of Medicine Research and Ethics Committee (SOM-REC) under registration number REC REF 2018-189. Patients' consent to participate in the study was waived by SOMREC as there was no direct interaction with patients but rather a review of their casualty assessment form.

\section{Consent for publication}

Not applicable.

\section{Acknowledgements}

We are indebted to the staff and patients of the emergency ward who participated in the study. We thank Miss Atto Esther for assistance in collecting the data, Miss. Bemanzi Juliana for assistance in doing the data analysis of this work and the HEPI project for training on manuscript writing.

\section{Funding}

This study was funded by the Rainer-Arnold Senior House Officers Training Support (RASHOTS) of Makerere University College of Health Sciences.

\section{Availability of data and materials}

The datasets used or analysed during this study are available from the corresponding author on reasonable request.

\section{Authors' contributions}


IK conceived and conducted the study with substantial contributions from MK and ES throughout the conduction of the study and writing of the manuscript. All authors critically revised the manuscript and approved the final version.

\section{Competing interests}

The authors declare that they have no competing interests.

\section{Author details}

1 Gastroenterology Division, Department of Medicine, Makerere University College of Health Sciences, PO BOX 7072 Kampala-Uganda

2 Mulago National Referral Hospital, P.O BOX 7051 Kampala-Uganda

\section{References}

Alatise, O. I., Aderibigbe, A. S., Adisa, A. O., Adekanle, O., Agbakwuru, A. E., \& Arigbabu, A. O. (2014). Management of overt upper gastrointestinal bleeding in a low resource setting: a real world report from Nigeria. BMC Gastroenterol, 14, 210. doi:10.1186/s12876-014-0210-1

Alema, O. N., Martin, D. O., \& Okello, T. R. (2012). Endoscopic findings in upper gastrointestinal bleeding patients at Lacor hospital, northern Uganda. Afr Health Sci, 12(4), 518-521.

Cummings, M. J., Goldberg, E., Mwaka, S., Kabajaasi, O., Vittinghoff, E., Cattamanchi, A., . . Davis, J. L. (2017). A complex intervention to improve implementation of World Health Organization guidelines for diagnosis of severe illness in low-income settings: a quasi-experimental study from Uganda.

Implementation Science, 12(1), 126. doi:10.1186/s13012-017-0654-0

Gralnek, I. M., Neeman, Z., \& Strate, L. L. (2017). Acute Lower Gastrointestinal Bleeding. N Engl J Med, 376(11), 1054-1063. doi:10.1056/NEJMcp1603455

Harries, A. D., \& Wirima, J. J. (1989). Upper gastrointestinal bleeding in Malawian adults and value of splenomegaly in predicting source of haemorrhage. East Afr Med J, 66(2), 97-99.

Laursen, S. B., Dalton, H. R., Murray, I. A., Michell, N., Johnston, M. R., Schultz, M., . . Stanley, A. J. (2015). Performance of new thresholds of the Glasgow Blatchford score in managing patients with upper gastrointestinal bleeding. Clin Gastroenterol Hepatol, 13(1), 115-121.e112. doi:10.1016/j.cgh.2014.07.023

Marmo R, K. M., Cipolletta L. (2008). Predictive factors of mortality from nonvariceal upper gastrointestinal hemorrhage: a multicenter study. American Journal of Gastroenterology, 1639-1647.

Peery, A. F., Crockett, S. D., Barritt, A. S., Dellon, E. S., Eluri, S., Gangarosa, L. M., . . Sandler, R. S. (2015). Burden of Gastrointestinal, Liver, and Pancreatic Diseases in the United States. Gastroenterology, 149(7), 
Rockall, T., Logan, R., Devlin, H., \& Northfield, T. (1996). Risk assessment after acute upper gastrointestinal haemorrhage. Gut, 38(3), 316-321.

Rukewe, A., Otegbayo, J. A., \& Fatiregun, A. (2015). CLINICAL CHARACTERISTICS AND OUTCOME OF PATIENTS WITH UPPER GASTROINTESTINAL BLEEDING AT THE EMERGENCY DEPARTMENT OF A TERTIARY HOSPITAL IN NIGERIA. Annals of Ibadan postgraduate medicine, 13(2), 89-93.

Siau, K., Chapman, W., Sharma, N., Tripathi, D., Iqbal, T., \& Bhala, N. (2017). Management of acute upper gastrointestinal bleeding: an update for the general physician. $J$ R Coll Physicians Edinb, 47(3), 218-230. doi:10.4997/jrcpe.2017.303

Siau, K., Chapman, W., Sharma, N., Tripathi, D., Iqbal, T., \& Bhala, N. (2017). Management of acute upper gastrointestinal bleeding: an update for the general physician. JOURNAL OF THE ROYAL COLLEGE OF PHYSICIANS OF EDINBURGH, 47(3), 219.

\section{Figures}

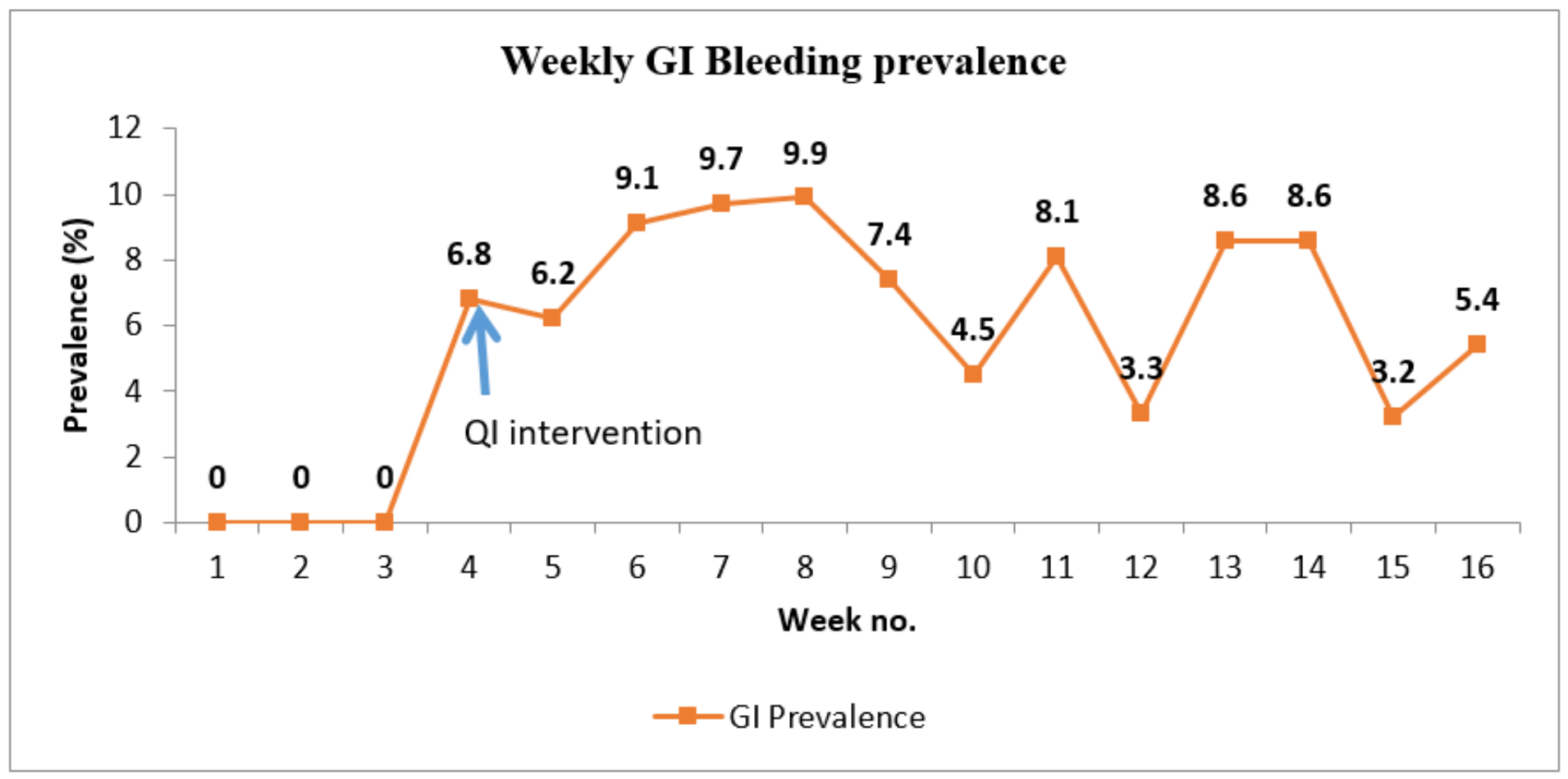

\section{Figure 1}

Run chart showing weekly prevalence of GI bleeding 


\section{Study flow diagram}

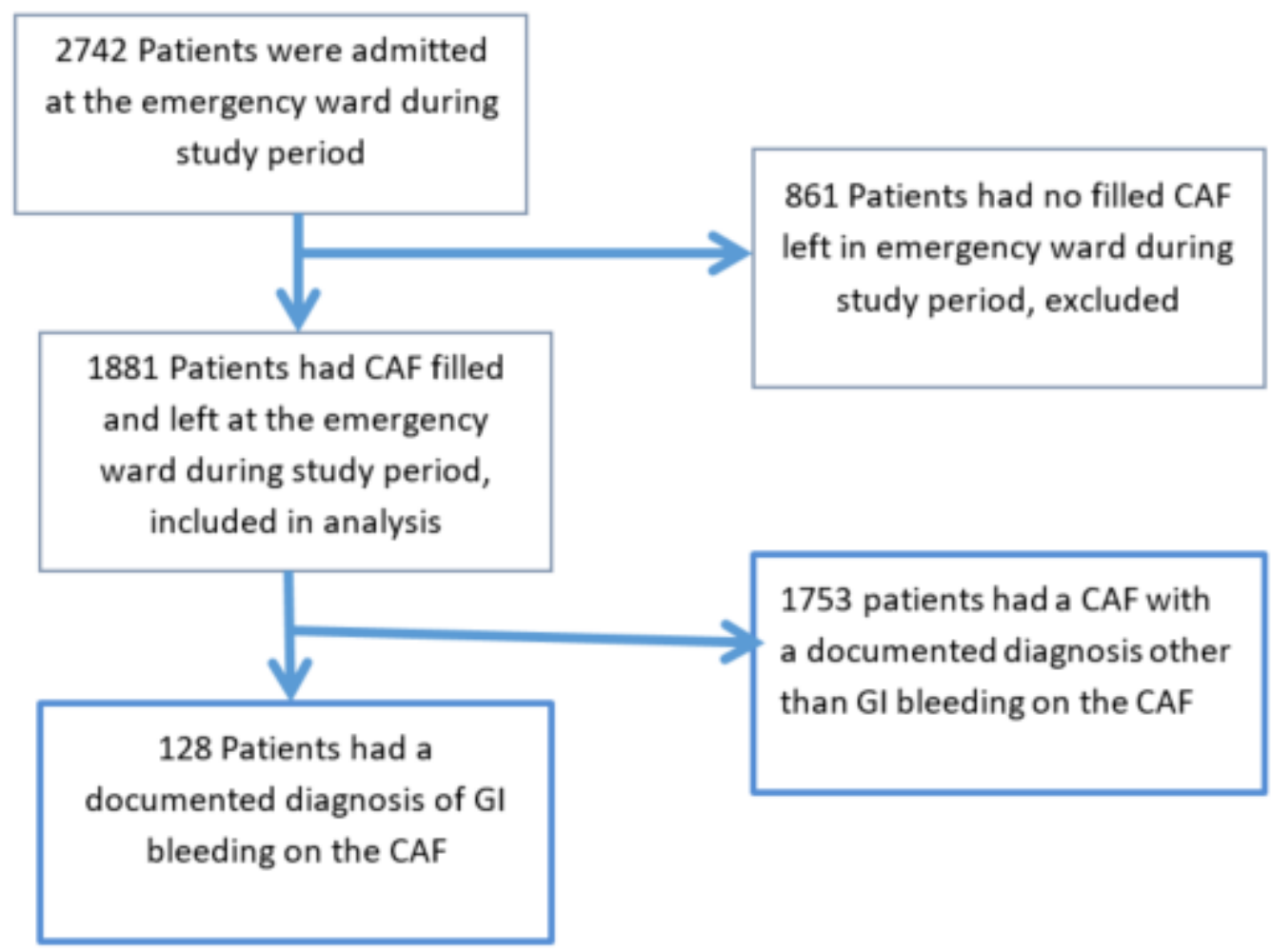

Figure 2

Study flow diagram 